\title{
Outcome of external cephalic version (ECV) in singleton pregnancy with uncomplicated breech presentation at term in a tertiary rural hospital
}

\author{
Sachin G. Vedpathak, Vaishali R. Korde Nayak*, Panigrahi P. P.
}

Department of Obstetrics and Gynecology, MIMER Medical College, Talegaon, Dabhade, Pune, Maharashtra, India

Received: 01 June 2017

Revised: 13 June 2017

Accepted: 08 July 2017

\section{*Correspondence:}

Dr. Vaishali R. Korde Nayak,

E-mail: vaishali2309@hotmail.com

Copyright: (c) the author(s), publisher and licensee Medip Academy. This is an open-access article distributed under the terms of the Creative Commons Attribution Non-Commercial License, which permits unrestricted non-commercial use, distribution, and reproduction in any medium, provided the original work is properly cited.

\section{ABSTRACT}

Background: Breech presentation is the most common malpresentation. The incidence of breech presentation at term is $3-4 \%$. Objective of present study was to evaluate the outcome of external cephalic version (ECV) in singleton pregnancy with uncomplicated breech presentation at term in tertiary rural hospital and to analyze the immediate and ultimate outcome of external cephalic version done in term pregnancy with breech presentation with gestational age $\geq 37$ weeks.

Methods: This study was conducted at MIMER Medical college and BSTR Hospital, Talegaon Dabhade. Patients with breech presentation at term were studied over duration of $2 \frac{1}{2} 2$ years. 50 patients with breech presentation $\geq 37$ weeks fulfilling the inclusion criteria underwent External cephalic version (ECV). Further obstetric progress is studied with the perinatal outcome and results were analyzed.

Results: ECV was successful in $66 \%$ cases, out of which $88 \%$ cases had vaginal delivery and $12 \%$ cases had LSCS for obstetric indication. Perinatal outcome was not affected with ECV.

Conclusions: ECV at term significantly reduces both the incidence of breech delivery and caesarean section rate for breech delivery. ECV does not adversely affect the maternal and perinatal outcome.

Keywords: Assisted breech delivery, Breech at term, External cephalic version

\section{INTRODUCTION}

Breech presentation is the most common malpresentation. The incidence of breech presentation at term is $3-4 \%$. Management of breech presentation at term is always being a topic of controversy. Day by day ECV is becoming a loosing Art. As delivery by Elective LSCS for Breech is associated with significantly lower neonatal mortality and morbidity, many obstetricians and pregnant women choose not to deliver breech babies vaginally.
This is a significant contributing factor in increasing the caesarean rate and associated maternal morbidity.

ECV has been definitely proven to decrease the incidence of breech at term. ${ }^{1}$ After rigorous scientific appraisal of several randomized controlled trials there has been renewed interest in external cephalic version in the last few years. ${ }^{2}$ American College of Obstetricians and Gynaecologists (2001) recommended that efforts should be made to reduce breech presentation by external cephalic version. ${ }^{3}$ 
This study was undertaken in our hospital with the intention of decreasing the incidence of breech presentation at term and ultimately decreasing complications associated with breech delivery and thereby also reducing the incidence of caesarean section for the same.

\section{METHODS}

This prospective study was conducted in the department of Obstetrics and Gynecology, MIMER Medical College over a period of 21/2 year from January 2013 to June 2015. 50 patients with uncomplicated breech presentation at term ( $\geq 37$ weeks) fulfilling the inclusion criteria underwent External cephalic version (ECV). Further obstetric progress is studied with the perinatal outcome and results were analyzed.

\section{Inclusion criteria}

- Singleton pregnancy with Uncomplicated breech presentation

- $\quad$ Term (gestational age>37 weeks)

- Adequate Liquor

- Uterus relaxed

- Adequate Pelvis

- Without any obstetric or medical complication

- Normal Feto-maternal Doppler.

\section{Exclusion criteria}

- Multiple pregnancy

- Preterm labour

- Severe Preeclampsia / Eclampsia

- Previous LSCS

- Short cord

- Feto-maternal complications

- Non reassuring NST

- placenta preavia

- Any contradiction for vaginal delivery.

- Patients who didn’t give consent.

- PROM

- Recent H/o vaginal bleeding

- Abnormal umbilical artery Doppler

- Congenital fetal anomaly

- Big fibroid.

All women fulfilling the inclusion criteria (with>37 weeks of gestational age with breech presentation) were included in the study. They were diagnosed as breech presentation during their antenatal visits in the third trimester with the help of clinical examination as well as USG. Pelvic assessment was done to see adequacy and to rule out any contradictory factor to vaginal delivery.

The procedure was explained in detail with its consequences and related complications to the pregnant woman and her relatives (mostly husband). Written informed consent was obtained from pregnant woman and her companion. USG was done to conform exact presentation, liquor assessment, placental localization, EBW and umbilical artery Doppler.

\section{Procedure}

ECV was planned as an OPD procedure without any anesthesia. 10 minutes before the procedure $0.25 \mathrm{mg}$ of terbutaline was given subcutaneously for tocolysis. NonStress Test (NST) was done before and after the procedure. Vitals and FHS were monitored every 5 minutes throughout the procedure.

ECV procedure - Pregnant woman was placed in supine position. Breech was first disimpacted from pelvis, and then actual version was accomplished using forward somersault method in which the flexion of fetal head was maintained by pressure with one hand on the fetal head and other on breech. When position changed to transverse lie, hands were interchanged and procedure was completed. If the version failed to occur backward flip was tried. If the initial attempt at ECV was unsuccessful, a second attempt was made immediately. Ultrasound was also used to aid version and visualize the fetal heart

After procedure, pregnant woman was kept under observation. NST was continued until a normal baseline rate and variability with at least three accelerations were seen. Inj Anti D was considered in case of Rh-negative mother. After successful version, once pregnant woman is comfortable and NST reactive, she is allowed to go home. If there was any concern about NST, or uterine irritability is noted, women were admitted.

\section{RESULTS}

Of the 50 women in whom ECV was done in our study, 33 were successful and 29 women delivered as vertex yielding success rate of almost $60 \%$. In present study, the mean age of women in the study group was $24.44 \pm 3.8711$ years. $80 \%$ patients are of age between 20-30 with average age 25 .

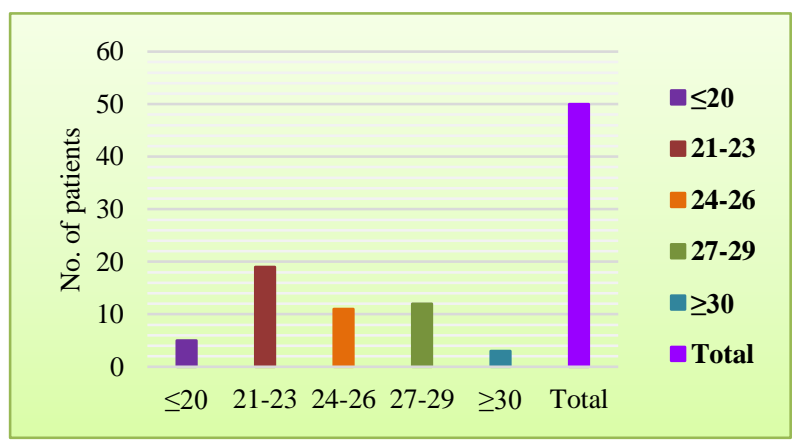

Figure 1: Age distribution of patients.

In this study, the mean gestational age was $37.72+-0.8$ weeks. It is interesting to note that ECV was more 
successful in multiparous women, in nulliparous women only $40 \%$ had successful ECV ( $p$ value $=0.9573>0.05$ ).

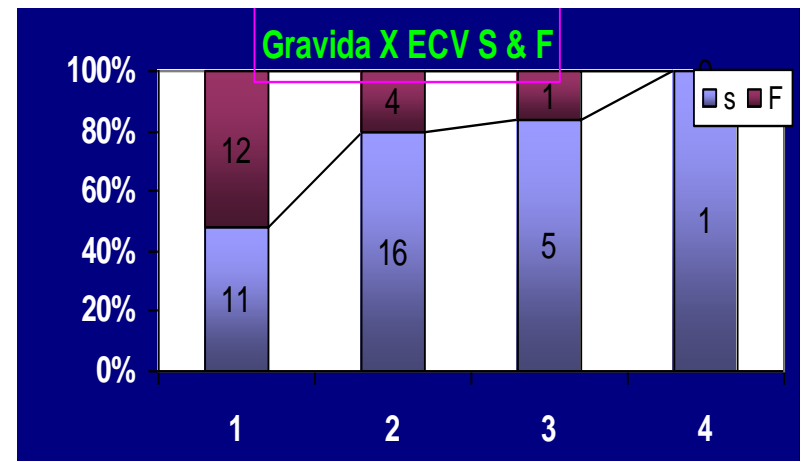

Figure 2: Showing relationship between gravida and successfulness of ECV.

Ratio of Engaged: Non Engaged Breech is 2:3 (Using Chi Square test $\mathrm{x}^{2}=0.0833 \mathrm{p}$ value $=0.7228>0.05$. ECV was successful three times more commonly in non-engaged than in engaged breech. Failure of ECV was two times more common in engaged than in non-engaged breech. In present study, out of 33 successful ECV Pregnant woman, $22(66 \%)$ were having complete (flexed) nonengaged breech, 3 (95) incomplete non-engaged breech, 2 (6\%) incomplete engaged breech. Out of 17 failed ECV patients $6(35 \%)$ were having incomplete engaged breech, $5(29 \%)$ complete engaged breech, 3 (18\%) complete non-engaged breech, 3 (18\%) incomplete non-engaged breech.

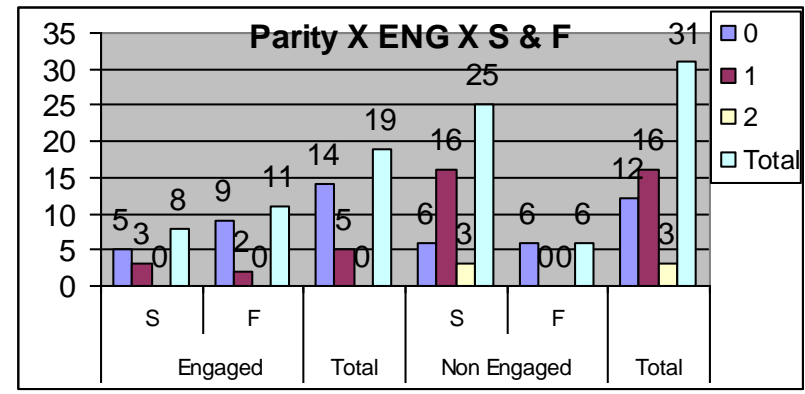

Figure 3: Association of parity with engagement of breech and success of ECV.

The ratio of successful and failed ECV in booked patients is 3:1 (Using Chi Square test $\mathrm{x}^{2}=0.48623 \mathrm{p}$ value $=0.4848>0.05)$.

Table 1: Association between gestational age and success of ECV according to booked, unbooked cases.

\begin{tabular}{|lllllll|}
\hline GA & Booked & & Unbooked & Tailed & Total \\
\hline 37 & Successful & Failed & Total & Successful & Failed & 4 \\
\hline 38 & 13 & 8 & 21 & 3 & 0 & 2 \\
\hline 39 & 12 & 0 & 12 & 2 & 0 & 0 \\
\hline Total & 6 & 5 & 11 & 0 & 1 & 6 \\
\hline
\end{tabular}

Out of total no. of ECV Done at 37 weeks $80 \%$ patients were booked in those patient's successfulness of ECV was $60 \%$. Mean gestational age was $37.72 \pm 0.8$ weeks. In present study, $>50 \%$ of failed ECV patients were having less AFI $(8-10 \mathrm{~cm}) .25 \%$ of failed ECV patients were having high AFI (14-17cm).

Table 2: Association of AFI with success of ECV and reversion.

\begin{tabular}{|llll|}
\hline AFI (cms) & Successful & Failed & Reversion \\
\hline $8-9.9$ & 0 & 9 & 0 \\
\hline $10-11.9$ & 11 & 3 & 0 \\
\hline $12-13.9$ & 19 & 1 & 0 \\
\hline $14-17$ & 3 & 4 & 3 \\
\hline
\end{tabular}

In present study in ECV successful patients average AFI was $12.24 \mathrm{~cm}$ but in ECV failed pregnant woman it was $10.8 \mathrm{~cm} .>50 \%$ of pregnancies that required LSCS were having AFI in the range of $8-9.9 \mathrm{~cm}$.
In present study transient, fetal bradycardia occurred in 4 $(8 \%)$ women out of 50 who underwent ECV. All 4 procedures were abandoned. In all these cases bradycardia was persistent and so were delivered by emergency caesarean section. In all babies had $1 \mathrm{~min}$ of APGAR score was 9.

Table 3: Occurrence of different complications of ECV.

\begin{tabular}{|lll|}
\hline Complications & ECV & ECV \\
\hline Fetal distress & 0 & Failed \\
\hline Abruption & 0 & 4 \\
\hline Cord prolapse & 0 & 0 \\
\hline
\end{tabular}

In present study only $18 \%$ (9) out 50 patients undergone more than one ECV procedure. In our study, $3(6 \%)$ out of 33 successful ECV had reversion and all reversion patients were parous women. 
In present study, out of 50 patients subjected for external cephalic version $66 \%$ (33) were successfully turned to cephalic presentation, of which $88 \%$ (29) had vaginal delivery and $12 \%$ (4) caesarean section delivery. In vaginal delivery group 28 women had spontaneous vaginal delivery and only one woman had instrumental vaginal delivery. In $34 \%$ (17) patients external cephalic version failed and all these patients had caesarean section. In this study 21 patients had caesarean section delivery, out of those 17 patients were in failed ECV group and 4 were in successful ECV group.

Table 4: Mode of delivery after ECV.

\begin{tabular}{|l|l|l|}
\hline & ECV & ECV \\
\hline & Successful & Failed \\
\hline Vaginal delivery & 29 & 0 \\
\hline LSCS & 4 & 17 \\
\hline
\end{tabular}

In failed ECV group most common indication for caesarean section was failed ECV 9 (53\%), followed by breech in labour $4(24 \%)$, fetal distress $4(24 \%)$. In successful ECV group most common indication for caesarean section was fetal distress $2(50 \%)$, failure to progress $2(50 \%)$.

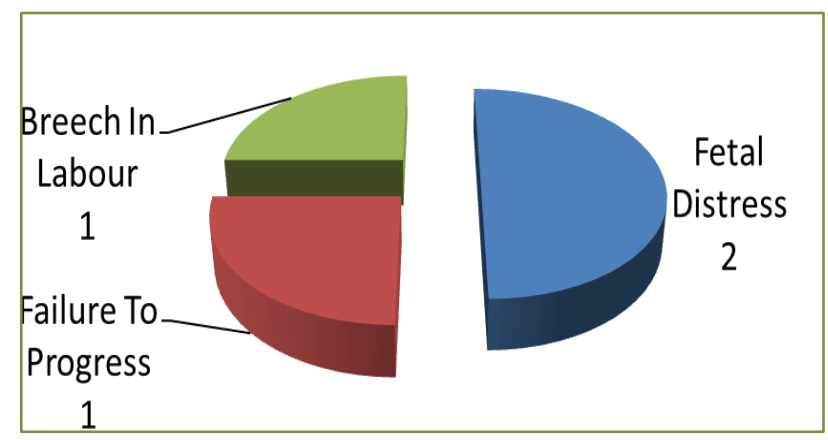

Figure 4: Indications for LSCS in successful ECV patients.

In current study, the mean birth weight of infants born to women in the study group was $2.897 \pm 0.3828 \mathrm{~kg}$. All baby had 1 minute APGAR of 9.

\section{DISCUSSION}

This study was designed to analyse the immediate and ultimate outcome of external cephalic version done in pregnancy with breech presentation with gestational age $\geq 37$ week. In the study by Hofmeyr the mean gestational age in those who underwent ECV was $37.5 \pm 0.93$ weeks. ${ }^{4}$ Patients with breech presentation after $\geq 37$ weeks gestation was considered for ECV. Studies in the Cochrane Database of Systematic Reviews provide evidence that external version at term reduces both the incidence of breech delivery and caesarean section rate for breech delivery. ${ }^{5}$ Present study provides additional evidence to support this, as the results demonstrate. Morrison et al reported that at a gestational age of 37 to
39 weeks, 179 out of 243 attempts (73\%) were successful in comparison with 28 out of 61 attempts $(45 \%)$ at 40 to 43 weeks $(\mathrm{p}<0.001)^{6}$

ECV at term differs in many fundamental ways from that performed before term. These include the fact that the fetus is mature and may be delivered more readily in the event of complications, and that spontaneous version without ECV attempt or reversion after successful ECV, are less common at term. A Cochrane review of ECV at term (beginning at 37 weeks) reported an increased likelihood that the fetus will be cephalic at the delivery and reduced caesarean sections. ${ }^{7}$

In present study, we used terbutaline as a tocolytic agent. The success rate of ECV is increased by use of tocolysis. This has been proved with ritodrine, salbutamol and terbutaline or with nefidepine. ${ }^{6,8-10}$ In present study ECV was successful in $40 \%$ of primigravidae and $90 \%$ of multigravidae. Parity has been associated with an increased rate and success by most authors. ${ }^{11}$ In randomized controlled trial by VanVeelan et al success rate of $25 \%$ and $29 \%$ were reported in nulliparous and multiparous women respectively. ${ }^{12}$ ECV successful patients average AFI was $12.24 \mathrm{~cm}$ but in ECV failed pregnant women it was $10.8 \mathrm{~cm}$. Other study also had the similar observation. ${ }^{13}$ Transient fetal bradycardia was the only complication occurred during procedure in 4 patients and underwent emergency caesarean section.NO evidence of nuchal cord or retroplacental clot was observed in these cases. Similar complication occurred in other studies.6,14,15 Reversion was more common in parous patients. Hutton et al found the rate of reversion of fetus to breech after a successful ECV was 4 of 34 $(11.8 \%)$ in the early ECV group and 1 of $18(5.5 \%)$ in the delayed ECV group. ${ }^{16}$

In present study $66 \%$ (33) had successful ECV of which $88 \%$ (29) had vaginal delivery. Stine et al reported $75 \%$ spontaneous vaginal delivery rate and $25 \%$ caesarean section rate for successful ECV group. ${ }^{14}$ All babies had 1 minute APGAR of 9. There was no admission to NICU. There were no fetal deaths attributable to ECV. Uterine rupture and fetal trauma were not experienced and suspected placental abruption occurred in $0.1 \%$. Lau et al reported out of 154 women who underwent ECV, 66.2\% had instrumental delivery and 265 had caesarean section the commonest indication being fetal distress and failure to progress. ${ }^{17}$ Similarly although our neonatal admission rate is similar to cephalic presentation at term due to small number of study group we cannot conclude that ECV does not increase neonatal admission rates.

\section{CONCLUSION}

From the present study, it may be concluded that ECV dose not adversely affect the maternal and perinatal outcome although more studies are required to confirm this. In our experience, ECV was more successful in multigravida with flexed breech presentation. Successful 
ECV reduced chances of caesarean section. Many obstetricians and Pregnant women still need to be convinced of the safety of ECV. However, our experience is very encouraging. The aim of this publication is to share our experience with other obstetricians especially newer generations to encourage them try ECV in breech $\&$ unstable lies. The art should not get lost with the older generation. While some case reports of complications exist for ECV procedures, but they are when performed by inexperienced operators without safety precautions, this does not mean that the procedure itself is inherently dangerous. Wrong selection of case can be the cause of failure. Our data suggest that women should be counseled that ECV is extremely safe but has a $0.5 \%$ risk of emergency caesarean section at the time of the procedure.

Funding: No funding sources

Conflict of interest: None declared

Ethical approval: The study was approved by the Institutional Ethics Committee

\section{REFERENCES}

1. Hofmeyr GJ, Kulier R. External cephalic version for breech presentation. In: The Cochrane Library Issue 1. Oxford Update Software; 2001.

2. Hofmeyr GJ, Kulier R. External cephalic version for breech presentation at term (Cochrane Review). In the Chochrane library, Issue 2. Oxford Update Software; 2002.

3. ACOG Committee on Obstetric Practice. Mode of term singleton breech delivery. Committee Opinion 265. Obstet Gynecol Can. 2003;25:14-6.

4. Hofmeyr GJ. Effect of external cephalic version in late pregnancy on breech presentation and caesarean section rate: a controlled trial. BJOG. 1983;90:392-9.

5. Hutton EK, Hofmeyr GJ, Dowswell T. External cephalic version for breech presentation before term. Cochrane Database Syst Rev. 2015;(7):CD000084.

6. Morrison JC, Myatt RE, Martin JN, Meeks GR, Marrin RW, Bucowaz ET et al. External cephalic version of breech presentation under tocolysis. AM J Obstet Gynecol. 1986;154:900-3.

7. Hofmeyr GJ, Kulier R. External cephalic version for breech presentationat term. Cochrane Database Syst Rev. 2005;2.
8. Van Dorsten JP, Schifrin BS, Wallace RL. Randomized control trial of external cephalic version with tocolysis in late pregnancy. Am J Obstet Gynecol. 1981;141:417-24.

9. Brocks V, Pholipsen T, Secher NJ. A randomized trial of external cephalic version with tocolysis in late pregnancy. BJOG. 1984;91:653-6.

10. Hofmeyr GJ. Interventions to help External cephalic versionfor breech presentation at term. Cochrane Database Syst Rev. 2004;1:000184.

11. American College of Obstetrics and Gynaecology. External cephalic version. Washington (DC): The College, 2000. Practice bullet in No:13

12. Vanveellen AJ, Van cappellen AW, Flu PK, Straub MJPF, Wallenburg HCS. Effect of external cephalic version in late pregnancy on presentation at delivery: a randomized controlled trial. BJOG. 1989;96:91621.

13. Brost BC, Scardo JA, Newman RB, Van Dorsten JP. Effect of fetal presentation on the amniotic fluid index. Am J Obstet Gynecol. 1999;181(5):1222-4.

14. Stine LE, Phelan JP, Wallace R. Update on external cephalic version performed at term. Obstet Gynecol. 1985;65;642-6.

15. Lau TK. Leung TY, Kit Lo KW, Fok WY, Rogers MS. Outcome of labour after successful external cephalic version at term complicated by isolated transient fetal bradycardia. BJOG. 2000;107:401-5.

16. Hutton EK, Kaufman K, Hodnett E, Amankwah K, Hewson SA, McKay D et al. Early external cephalic version trial group. external cephalic version beginning at 34 weeks' gestation versus 37 weeks' gestation: a randomized multicenter trial. Am J Obstet Gynecol. 2003;189(1):245-54.

17. Lau TK, Wing K, Rogers M. Pregnancy outcome after successful external cephalic version for breech presentation at term. Am J Obstet Gynecol. 1997;176:218-23.

Cite this article as: Vedpathak SG, Korde Nayak VR, Panigrahi PP. Outcome of external cephalic version (ECV) in singleton pregnancy with uncomplicated breech presentation at term in a tertiary rural hospital. Int J Reprod Contracept Obstet Gynecol 2017;6:3528-32. 